\title{
HOUSE: \\ Semânticas teológicas do desencantamento humano em um seriado de TV
}

\author{
HOUSE: \\ Theological semantics of human disenchantment in a TV series
}

\section{Renato Machado*}

\section{RESUMO}

O artigo analisa a pergunta sobre o humano do ponto de vista da Teologia a partir do seriado televisivo House M. D. O autor destaca as crises humana diante da dor, da solidão e dos valores, concluindo com a afirmação do sintoma do desencantamento da condição humana.

Palavras-chave: House M. D. Sentido. Vida humana. Teologia.

\section{ABSTRACT}

This article analyses the question of the human from the viewpoint of Theology drawing from the TV series House M.D. The author highlights the human crises facing pain, solitude and values, concluding with the affirmation of the symptom of disenchantment of the human condition.

Keywords: House M.D. Sense. Human Life. Theology.

* Mestre em Teologia - PUCRS. Professor da Faculdade Dom Bosco e Coordenador de Pastoral. E-mail: <gaulkemachado@terra.com.br>.

\begin{tabular}{|l|l|l|l|l|l}
\hline Teocomunicação & Porto Alegre & v. 45 & n. 1 & p. 38-58 & jan.-abr. 2015 \\
\hline
\end{tabular}




\section{Introdução}

O que sobrou do ser humano neste início de século XXI? Melhor dizendo, que humanidade emerge da modernidade tardia, que insistimos em já nomear como pós-modernidade? Indubitavelmente, uma variada gama de respostas pode vir ao encontro destas perguntas, lançando olhares através de tantos prismas quantos são possíveis ao conhecimento humano. Partindo-se da Filosofia, por exemplo, poder-seia levantar questões como as da hipermodernidade, do pós-moralismo e da sociedade da decepção, conforme as categorias construídas por Gilles Lypovetsky, bem como toda teoria da complexidade formulada por Edgar Morin. Na Sociologia, encontraríamos pistas em concepções como a modernidade líquida, de Zygmunt Bauman, e na ideia de sociedade em rede, de Manuel Castells. Na Neurociência nos depararíamos com as recentes construções de identidade humana a partir do conhecimento do cérebro e seu complexo funcionamento, em teorias defendidas, por exemplo, pelo brasileiro Miguel Nicolelis. Enfim, seria uma lista infindável de concepções acerca de nossa situação no tempo presente, cada uma com sua complexidade, suas possibilidades e seus limites. Neste artigo, fazemos opção por um ponto de vista bem definido para buscar respostas a estas perguntas: sem desconsiderar nada daquilo que tem sido elaborado por essas diversas áreas do conhecimento, realizaremos nosso itinerário pelos caminhos da Teologia. Não sendo também nossa intenção realizar um inventário das categorias a respeito da condição humana elaboradas na teologia, sintetizaremos a questão da relevância teológica a esse respeito com uma proposição: talvez, algumas das respostas importantes que a Teologia possa oferecer no tempo atual digam respeito aos discursos de fé elaborados sobre as realidades que percebemos e as identidades que construímos. Tratando-se especificamente da Teologia elaborada a partir da experiência cristã, como é o caso, pode-se dizer ainda que estes discursos de fé estão culturalmente embasados no ideário judaicocristão e são motivo de crise para o projeto de realidade e identidade nascidos desta tradição religiosa, que é um dos grandes referenciais arquetípicos do mundo ocidental. Perguntar pelo humano que emerge neste tempo a partir da Teologia, então, pede uma reformulação da pergunta que propomos inicialmente: Quem o ser humano acredita ser neste início de século XXI? Como se configura a realidade a partir dessa crença? Junto a isso, cabe também o seguinte questionamento: Quem, 
realmente, é este ser humano e como ele pode reaproximar-se de uma identidade original? Essas perguntas são teológicas e, dificilmente, quaisquer outras áreas do conhecimento poderiam respondê-las.

Afirmar que a identidade humana e a realidade são construídas a partir de crenças a respeito delas traz também a pergunta a respeito do que embasa essas crenças, uma vez que todo ato de fé pressupõe uma experiência de sacralidade. Ora, se a Teologia e o ambiente sagrado institucional vêm perdendo sua universalidade e migrando para a particularidade de grupos determinados e suas respectivas crenças, fazse necessário investigar a existência de novos lugares, onde de fato estejam ocorrendo experiências universalizantes de sacralidade no tempo atual. Nisso, seguramente, podemos apontar o ambiente midiático como lócus relevante. Considerando-se que o desenvolvimento rápido dos meios de comunicação de massa e a consequente implementação de uma indústria cultural no mundo ocidental tiveram boa parte da responsabilidade nas mudanças de paradigma em nosso contexto social, podemos facilmente constatar que o envolvimento e a afinidade de grandes parcelas populacionais com produções cinematográficas, televisivas, musicais e, mais recentemente, a intensidade com que acontecem as conexões a redes sociais e outras instâncias do mundo virtual, revelam dimensões de uma busca por sentido e significância para a vida. Chegamos, com isso, a outra delimitação necessária a este escrito: assumindo o contexto midiático como lócus teológico, o que, especificamente, tomaremos como objeto de análise no vasto campo das produções de mídia para elaborarmos um discurso teológico sobre identidade humana na atualidade e que ponto de vista adotaremos?

Por isso, desde já, queremos deixar claro que não abordaremos o contexto de mídia como um lugar profano que se contrapõe a um lugar sagrado, legitimado institucionalmente. Reconhecendo toda idolatria provocada e existente na mídia - idolatria que não deixa de existir, de forma tão prejudicial quanto, nas tradições e instituições religiosas abordamos essas produções como expressões da transcendência humana. Tratando-se de labor artístico, assumimos que sua gênese se dá a partir de elementos de inspiração, portadores de uma revelação, provocada pela intensidade da experiência estética que se estabelece no contato com a obra. ${ }^{1}$ Mantemos, assim, um diálogo de categorias teológicas

1 CALVANI, Carlos Eduardo. Teologia da arte. São Paulo: Paulinas. São Paulo: Fonte Editorial, 2010. p. 76-77. 
com as produções culturais, levantando a seguinte suspeita: Muito mais do que oferecer modelos prontos, não seriam essas produções o lugar onde emergem alguns dos arquétipos mais representativos da identidade humana deste tempo? Que opção fazer em um campo tão vasto quanto o das produções culturais midiáticas? Há muitas alternativas válidas e que resultariam em excelentes análises e pesquisas, porém, em se tratando de arte, o critério que mais pesa neste tipo de escolha é a preferência do próprio autor. Afinal, se vamos tratar de experiência estética, não podemos subtrair aquilo que pessoalmente vivemos neste sentido. Assim, dentre tantas produções artísticas, optamos por uma que nos impactou e atraiu a ponto de, involuntariamente, nos levar a uma leitura teológica de seu conteúdo: o seriado televisivo House M.D.

House é um drama hospitalar, ou seja, suas histórias são desenvolvidas a partir de tramas envolvendo a saúde humana, seus problemas e todos os sentimentos envolvidos neste tipo de situação. A identificação do espectador com uma série portadora desta temática é, portanto, óbvia: todos adoecemos e vivemos o drama de buscar a cura para nossas enfermidades e a recuperação para nossa saúde. Da mesma forma, todos nós já acompanhamos alguém em consultas a médicos ou internações hospitalares. Alguns de nós, certamente, já vivemos a crise da perda de pessoas próximas em consequência de alguma enfermidade que não pôde ser revertida. Junto a isso, a grande maioria das pessoas que busca cuidados médicos provavelmente alimenta certa curiosidade sobre o cotidiano dos profissionais da saúde, perguntando-se, por exemplo, como as pessoas desta área conseguem descobrir que enfermidade está ameaçando a saúde de alguém através da observação de sintomas, ou, ainda, como se sentem estes profissionais ao realizarem uma intervenção cirúrgica em um paciente. Há curiosidade, também, acerca da vida privada de médicos e médicas: De que forma alguém que lida com a saúde, a vida e a morte de muitas pessoas, resolve seus problemas, cuida de suas relações e de sua própria saúde? Não raramente, aliás, profissionais da saúde gozam de certa fama de santidade, sendo vistos pela maioria da população como pessoas abnegadas, que renunciam à própria vida para cuidar e salvar a vida alheia. São os bons samaritanos, que se dedicam ao próximo, não importando quem seja este próximo. Pessoas que, certamente, são exemplos a serem seguidos. Pensando-se por este viés, poderíamos enumerar vários seriados que, ao longo de 
décadas, têm narrado histórias embasadas nestas questões e perguntas, consagrando personagens que, certamente, inspiraram muitas pessoas a seguirem carreira nesta área. House insere-se nesta linha de dramaturgia, mas revela-se completamente diferente. As histórias exibidas semanalmente mostram, sim, personagens que enfrentam o drama de lutar pela cura de enfermidades, bem como todos os outros elementos que compõem o medical drama: o hospital que serve de cenário para as narrativas, o núcleo de personagens-médicos, com seus dramas pessoais, personalidades marcantes e atos de heroísmo. Há, porém, um fator que, agindo como um catalizador no ambiente do seriado, desconstrói aquilo que se esperaria de um seriado hospitalar: o personagem principal, Dr. Gregory House.

\section{Dor e solidão: um estado teológico}

Diagnosticologista que chefia uma equipe médica multidisciplinar, House é considerado uma autoridade em sua área, assumindo apenas casos nos quais a enfermidade se apresenta de forma tão misteriosa que o diagnóstico correto fica praticamente impossibilitado. Seu grande talento é o de desvendar esses mistérios através da leitura dos sintomas apresentados no paciente, o que, na maioria das vezes, constitui-se em um verdadeiro enigma para ele e os demais membros da equipe. Fosse apenas isso, não haveria nada de novo. O diferencial que o seriado apresenta é que o grande enigma que House precisa desvendar não é outro senão ele próprio. Racional e pragmático ao extremo, o médico é obcecado pela verdade a ponto de ter desenvolvido um acurado senso de observação e uma intuição fora do normal. Por essa razão, House realiza uma leitura de mundo a partir daquilo que ele distingue como realidade, em meio às tantas ilusões assumidas pelas pessoas com quem ele convive e a quem atende. O ponto central disso tudo encontra-se em um problema que atinge o personagem e que, mesmo compreendido racionalmente por ele, torna-se um mistério muito maior que a totalidade de seus conhecimentos: a dor. House tomou uma decisão equivocada a respeito de uma enfermidade que o acometia e, como consequência, passou a sentir dores crônicas, que só podem ser aliviadas através de um fortíssimo analgésico, do qual ele se tornou dependente. Ele sabe, portanto, a origem de seu sofrimento e compreende os motivos pelos quais continua sofrendo, mas vive a 
angústia de não compreender o sentido de viver o sofrimento. Com a dor, vieram a amargura e a solidão e, com elas, a absoluta incapacidade de lidar com pessoas. House, portanto, é um médico doente e viciado que, por não conseguir lidar com suas próprias dores, prefere a solidão. Ao mesmo tempo, esse sofrimento o leva a identificar os sofrimentos alheios e os analgésicos emocionais ou sociais nos quais os outros se viciam para não sofrer. Para House, todos mentem e ninguém realmente muda. Assim sendo, ele não vê necessidade em manter aparências ou agradar a quem quer que seja.

Ao longo de oito anos, este herói improvável levou milhões de pessoas, no mundo inteiro, a acompanharem a história de sua dor e de muitas outras dores alheias que a série apresentava. Em termos de identificação com o público, portanto, este quadro apresenta algo que, não sendo inédito, é, no mínimo, inusitado no atual contexto cultural. A identificação não se baseia em histórias de superação do sofrimento ou abnegação para aliviar o sofrimento alheio, como é comum na dramaturgia norte-americana, mas na integração do sofrimento com a vida. O seriado, assim, acaba travando o seguinte diálogo com seu público: todos sofrem e ninguém deseja sofrer e o que se faz a respeito disso define muito daquilo que acabamos nos tornando. Outro elemento importante nesta análise é a pergunta sobre o tipo de modelo a que Gregory House se acaba tornando, uma vez que esta, geralmente, é a função do personagem principal. Considerando-se que, geralmente, ao abordarmos conceitos como modelo e exemplo, estamos nos referindo ao que se aspira como ideal de vida, House facilmente pode ser identificado como oposto disso. Por outro lado, se abordarmos modelo e exemplo como categorias que revelam realidades que nem sempre estão suficientemente esclarecidas no cotidiano, então House se torna algo inigualável. Nesse sentido, pode-se aqui abordar o seriado, especialmente na figura de seu personagem principal, na qualidade de um arquétipo, que sintetiza em si algumas das grandes questões e características dos tempos em que vivemos. Ao assumirmos esta ideia, já podemos intuir que tipo de revelação e inspiração pode vir da série. House revela o que sobrou do ser humano no final do século XX, que humanidade emerge neste início de século XXI, que discursos de fé sustentam estes modelos e que perspectiva de superação e libertação destes modelos podem ser intuídas nesta dinâmica de relações. 


\section{Uma questão de valores}

No primeiro episódio da oitava e última temporada da série, ${ }^{2}$ House está preso. Depois de ter destruído a casa da diretora do hospital com um automóvel, por não aceitar o final do relacionamento amoroso entre os dois, o médico é condenado a um ano de prisão. Abrindo mão de qualquer defesa, ele opta por cumprir sua pena integralmente, mesmo com a possibilidade de responder o processo em liberdade. House acredita que está melhor longe das pessoas. Na sequência de abertura, o médico está em uma audiência na qual vai se decidir sobre a possibilidade de sua liberdade condicional.

Promotor: Como teve um comportamento razoável e cumpriu oito dos doze meses de pena, podemos conceder a liberdade condicional na sexta-feira, daqui a cinco dias. Você se arrepende do que fez?

House: Sim.

Promotor: Sim?

House: É a resposta certa, não?

Promotor: Está querendo nos irritar?

House: Não. Só quero dar as respostas que vocês precisam ouvir para não terem maiores problemas e assim possam preencher os formulários e me soltar.

Advogada: Precisa mostrar remorso.

House: É assim que o sistema funciona? Soltam os melhores atores? Tremo só de pensar...

Advogada: Você entrou com o carro na casa da ex-namorada e ficou três meses fora do país.

House: Eu sabia que a filha dela estava com a avó, como fazia às sextas, e vi que todos tinham ido para a sala.

Advogada: Poderiam ter voltado.

House: Eu teria percebido, já que fui pra cima deles.

Promotor: Cale-se! Temos que diminuir a superlotação, mas serei claro: se responder a algum carcereiro, se levar alguma bandeja para a cela, se infringir qualquer regra, vai ficar aqui por mais

2 VINTE Vicodins. In: HOUSE - OITAVA TEMPORADA. Escrito por Peter Blake. Dirigido por Greg Yaitanes. Produzido por Marcy G. Kaplan: Universal Studios, d2011. 1 DVD (43 min.), widescreen, color. Episódio 1. 
quatro meses. Esqueça o arrependimento. Consegue ficar cinco dias sem arranjar encrenca?

House: Consigo. ${ }^{3}$

É assim que o sistema funciona: argumentos sensatos não bastam, é preciso dramatizar, pois são os sentimentos que revelam a verdade. Certamente, se House abrisse seu coração e, em meio a um choro angustiado, falasse do quanto sua vida é sofrida, teria conquistado sua liberdade automaticamente. Ele teria tocado seus juízes e estes conseguiriam compreendê-lo, mesmo que não o perdoassem. Mas, não, ele não está angustiado. Seu arrependimento não é sentimental, mas racional. Ele sabe o que fez e acredita que sua ex-namorada merecia isso dele. Seu arrependimento provavelmente se relacione apenas com a perda de tempo que ele está tendo na prisão. Ele é um desgraçado, um miserável e está muito bem sendo assim. Isso é desconcertante para o grupo que, representando a justiça e a própria sociedade, se coloca diante dele. A expectativa do promotor, da advogada e dos outros é que House se mostre mais humano e, portanto, apto a voltar ao convívio social. Acreditam que isso se mostra emocionalmente. O que os pega desprevenidos é que House se mostra humano, de um jeito que eles não conseguem prever ou controlar.

Um dos aspectos mais fascinantes do medical drama mais assistido de todos os tempos é a capacidade do personagem principal de descrever o comportamento da natureza humana como se possuísse um manual de instruções a respeito disso. Criticando atitudes e provocando reações nos outros personagens, Dr. House resume as regras sociais que seguimos e nosso comportamento demonstrando como frequentemente são nossos temores e hipocrisias que os criam e, sobretudo, justificam. (Tradução nossa) ${ }^{4}$

A expectativa de um bom comportamento por parte das pessoas é uma herança, senão teológica, pelo menos religiosa, que carregamos em nossa convivência. A redução da experiência do sagrado ao âmbito moral retirou o caráter mistagógico da dimensão religiosa, tornando-a, quase

3 VINTE Vicodins. In: HOUSE - OITAVA TEMPORADA. Escrito por Peter Blake. Dirigido por Greg Yaitanes. Produzido por Marcy G. Kaplan: Universal Studios, d2011. 1 DVD (43 min.), widescreen, color. Episódio 1.

4 GOSO, Diego. Il Vangelo secondo... Dr. House. Cantulapa: Effatà, 2010. p. 35. 
que, exclusivamente, em fidelidade doutrinária. Esta fidelidade, por sua vez, foi se traduzindo em atitudes pessoais que, em conformidade com a doutrina, garantiam a salvação pessoal. O estabelecimento de um estado laico, a partir do século XVIII, provocou uma mudança de referenciais quanto a esta fidelidade. Desvinculando-se da questão religiosa, buscavase o cultivo de deveres em relação a si para garantir o estabelecimento de valores sociais. Essa dinâmica social, de certa forma, foi tornando o ser humano um instrumento de si mesmo, pois, ao cultivar determinados valores sociais, estaria trilhando o caminho para a felicidade e liberdade, ao mesmo tempo em que auxiliava na construção de uma sociedade livre e feliz. Nesse sentido, pode-se afirmar que a identidade humana, em boa parte, era definida pela observância ou não desses valores e atitudes pessoais. Obviamente, esses valores e atitudes nascem em uma sociedade movida pelo trabalho e produtividade, na qual o progresso se torna o sacramento de confirmação dessa mesma sociedade e de cada pessoa que a compõe. Se, nos tempos atuais, encontramos essa rigidez moral abalada, não se pode afirmar que a sociedade abriu mão de toda e qualquer atitude pessoal como idealização da identidade humana. $\mathrm{O}$ que se observa, por isso, é a manutenção de valores pessoais, mas em face à opinião alheia e não a si mesmo, ou seja, perde-se o valor das expectativas pessoais em detrimento da hipervalorização da imagem pública e daquilo que se espera como atitude de alguém em determinado contexto. Muito mais do que atitudes assumidas por crença pessoal a respeito da própria identidade, os valores alardeados e apregoados na cultura neoliberal se tornam uma questão de gestão pessoal, que permite a manutenção de um status produtivo no mercado de trabalho. Resulta disso uma moral sem substância, uma vez que esta é imposta ao indivíduo como vigilância da sociedade sobre ele e não como resposta livre e consciente à existência. ${ }^{5}$ Por isso, House não se mostrou angustiado; ele não estava.

No tocante a cada indivíduo, as obrigações de ordem interna ficaram obsoletas, mas a nova cultura sanitarista e profissionalizante não cessa de promover uma interiorização das normas coletivas. Ninguém põe em dúvida que a depreciação da moral individual tenha o sentido de um avanço ainda mais acentuado da lógica histórica do individualismo, desde que se tenha presente que o poder

5 LIPOVETSKY, Gilles. A sociedade pós-moralista. Barueri: Manole, 2005. p. 59-61. 
social de regularização dos comportamentos continua atuante, embora de modo totalmente diverso. O acréscimo de autonomia subjetiva só se compreende em conexão com um acréscimo de controle social heterônimo. Este, efetivando-se em razão do próprio interesse de cada indivíduo, é capaz de criar, cada vez mais, novas regulamentações existenciais, na órbita de um novo consenso social e sem injunções de natureza autoritária. ${ }^{6}$

Nesse contexto emerge aquilo que parece ser a grande marca do discurso dramatúrgico de House: o desencantamento a respeito dos modelos de normalidade que são impostos ao ser humano deste tempo, que, acreditamos, guarda fidelidade ao estilo teológico de autores como Paul Tillich e Jürgen Moltmann. Nesse sentido, parece oportuno que, neste momento de nosso artigo, nos refiramos mais diretamente ao termo "desencantamento", que adotamos como título. Obviamente, não se pode fazer uso deste termo sem uma referência a Max Weber, que, de certa forma, o coloca como chave de leitura para a compreensão do pensamento cultural do ocidente, em sua obra clássica A Ética Protestante e o Espírito do Capitalismo. Habitando o campo da sociologia, Weber busca entender o Zeitgeist da sociedade capitalista a partir da presença de confissões protestantes de forma majoritária onde florescem a propriedade privada e a livre iniciativa de mercado. Não é nossa intenção realizar um aprofundamento nesta obra ou tomá-la como referencial teórico, mas faz-se necessária uma pequena referência a um aspecto que consideramos importante. Para Weber, as sociedades eminentemente protestantes, ao eliminarem a magia de seu horizonte soteriológico, passaram a identificar salvação com o próprio progresso de suas vidas. O autor denomina essa atitude de ascese intramundana, ou seja, o cultivo de rigorosos hábitos religiosos de maneira inserida na realidade, tornando toda e qualquer obra pessoal um testemunho da glória de Deus. Nesse sentido, Weber contrasta a atitude católica de seu tempo - que parecia exortar a uma fuga do mundo - com a atitude protestante de viver no mundo segundo a vontade de Deus. Esse viver no mundo, porém, trazia uma crise bastante séria: era necessário passar do status naturae a um status gratiae sem fugir da realidade. Isso exigia profunda racionalidade, pois tudo precisava ser pensado tendo uma santificação intramundana no horizonte. Daí, segundo o autor, deriva-se

6 LIPOVETSKY, 2005, p. 62. 
uma visão de mundo que procura desvendar a essência daquilo que é vivido para que a existência não perca seu norte. ${ }^{7}$

$\mathrm{O}$ atual contexto sociocultural parece trazer de volta uma espécie de reencantamento que, se não leva a uma negação do mundo, acaba provocando certa alienação a respeito da realidade. Assim, observa-se um ser humano encantado pelas possibilidades de autorrealização e sucesso financeiro, tendo por horizonte final uma identidade de celebridade. Essa dinâmica, por sua vez, é alimentada por uma teologia de prosperidade, embasada em manuais de autoajuda, que leva à crença de que tudo na vida se resolve com esforço e trabalho. Por sua vez, o dado explicitamente religioso, no panorama de reencantamento, retoma ares verdadeiramente medievais, com uma espiritualidade de demonização das questões cotidianas e busca por purificação para que se tenha uma vida melhor. Quanto à morte, ela acaba sendo extirpada da existência e isolada em alas de UTI, em cemitérios assépticos e uniformemente organizados e no silenciamento a respeito de sua existência. ${ }^{8}$ De certa forma, pode-se observar House sob o prisma de um protesto contra essa condição. $\mathrm{O}$ personagem vive uma espécie de ascese intramundana ao rejeitar boa parte daquilo que é considerado normalidade em seu contexto, tomando por horizonte soteriológico a revelação da verdade sobre as pessoas e as relações entre estas, mesmo com esta verdade causando rompimentos irreconciliáveis entre os que a assumem. Por isso afirmamos que o personagem é desgraçado e miserável, pois assume na própria pele um desencantamento digno dos mais antigos ascetas. Como criatura humana ele se vê tão longe de qualquer graça ou misericórdia que sua resposta acaba sendo o sarcasmo sobre sua desgraça e a desgraça alheia.

\section{A identidade humana como sintoma: o desencantamento da condição humana}

Aquilo que reconhecemos como humanidade, seja em seu sentido coletivo, seja em seu sentido pessoal, é um conceito construído. Não poderia ser diferente, uma vez que parece não existir nenhuma instância fora do humano que poderia fornecer modelos prontos de identidade.

7 WEBER, Max. A ética protestante e o espírito do capitalismo. São Paulo: Companhia das Letras, 2012.

8 BAUMAN, Zygmunt. O mal-estar da pós-modernidade. Rio de Janeiro: Jorge Zahar, 1998. p. 194-195. 
O ser humano nos é revelado em sua complexidade: ser, ao mesmo tempo, totalmente biológico e totalmente cultural. O cérebro, por meio do qual pensamos, a boca, pela qual falamos, a mão, com a qual escrevemos, são órgãos totalmente biológicos e, ao mesmo tempo, totalmente culturais. O que há de mais biológico - o sexo, o nascimento, a morte - é, também, o que há de mais impregnado de cultura. Nossas atividades biológicas mais elementares - comer, beber, defecar - estão estreitamente ligadas a normas, proibições, valores, símbolos, mitos, ritos, ou seja, ao que há de mais especificamente cultural; nossas atividades mais culturais - falar, cantar, dançar, amar, meditar - põem em movimento nossos corpos, nossos órgãos; portanto, o cérebro. ${ }^{9}$

House não faz outra coisa senão lidar com os fatos biológicos mais centrais para o ser humano - viver e morrer -, desconstruindo toda carga moral e cultural que essas questões carregam com elas. Nesta desconstrução, fica-se com a impressão de que, além do diagnóstico para a enfermidade, o médico quer chegar a um diagnóstico a respeito da identidade formada naquela pessoa, identidade essa que, geralmente, tem alguma relação com a própria enfermidade que está sendo tratada. Por essa razão, House parece apresentar-se como um anarquista que ignora qualquer tipo de regra social estabelecida. Se todo mundo mente, as identidades humanas adotadas como padrão na sociedade podem ser mentiras muito bem contadas e encenadas, muitas vezes, ao longo de toda uma vida. Qual é, então, a compreensão de humanidade que emerge do seriado?

Se, conforme a afirmação de Morin, a síntese entre o biológico e o cultural é o fator que vai definindo o rosto humano no mundo e na história, pode-se intuir que nunca houve e dificilmente haverá algo de definitivo a ser dito a respeito dessa questão. Por outro lado, há fatores que, por mais que recebam releituras ao longo do tempo, continuam perenes na existência humana: nascer e construir a própria identidade de forma histórica, experimentar os limites e potencialidades do próprio corpo ao criar consciência sobre ele e sobre a vida em si e saber que o fim desta vida é inevitável, ainda que não se saiba exatamente a finalidade da própria vida. Essas são, sem dúvida, as mais autênticas experiências que a humanidade tem realizado. Nisso se denota uma primeira questão

9 MORIN, Edgar. A cabeça bem-feita: repensar a reforma. Reformar o pensamento. Rio de Janeiro: Bertrand Brasil, 2003. p. 40. 
importante: a identidade humana e o entendimento de uma condição humana são definidos pela indefinição, ou seja, a maior característica que transparece em homens e mulheres é a de buscar sempre um sentido para o todo da existência, mesmo com a intuição de que este nunca será alcançado. Dessa forma, quaisquer definições éticas e morais que, historicamente, se constroem como parâmetro de convivência humana precisam sempre ser revisadas, relativizadas e reformadas, sob o risco de se tornarem prisões existenciais que impedem o ser humano de responder à sua essência vocacional, ou seja, de eterno perguntador e buscador de respostas.

Na imagem de Pascal, o ser humano é anjo e burro ao mesmo tempo: quem desejar ser um anjo ou um burro exclusivamente cairá no inferno, pois a salvação do inferno está na aceitação das contradições, onde mora a verdade e a humildade. Desta forma, precisa-se superar o demoníaco que busca pretensões totalitárias e últimas, pois o inferno passa a existir quando se aceita apenas um dos lados, excluindo outras realidades sociais e individuais principalmente a realidade básica do ser e do não ser. ${ }^{10}$

Guardando radicalidades opostas em si, o ser humano apresenta-se como ente fragmentado que persegue a possibilidade da unidade, sendo que esta busca é exatamente aquilo que se pode definir por existência ou, simplesmente, por vida. Para que esta jornada à procura de sentido histórico seja desencadeada, portanto, a primeira condição é a de que o indivíduo assuma sua incompletude e se sinta incomodado por isso. A segunda é que, saindo de uma inércia inicial, a pessoa se coloque a caminho. Entre uma coisa e outra, porém, faz-se necessário um despertar para a busca, o que pode se apresentar das mais diferentes maneiras. Para Tillich, essa dinâmica resulta em uma possibilidade de unidade existencial do ser humano, apontada pelo teólogo como imperativo moral. É através dele que as dimensões culturais e religiosas mantêm-se integradas à totalidade da vida, sem desintegrar-se em vazios estéticos, no caso da primeira ou em distorções emocionais mistificadas, no caso da segunda. Por imperativo moral, Tillich não se refere ao simples seguimento de

\footnotetext{
${ }^{10}$ DE SOUZA, Vitor Chaves. "O inferno está vazio e os demônios estão aqui”: uma reflexão existencialista sobre a história dos infernos em diálogo com o demoníaco em Paul Tillich. Correlatio, Brasil, 10. mar. 2012. Disponível em: <https://www.metodista.br/revistas/ revistas-ims/index.php/COR/article/view/2973>. Acesso em: 22. jun. 2013. p. 63.
} 
regras sociais, mas a um compromisso ético com as demandas de justiça em cada época. Esse seria o elemento que conferiria uma seriedade última a todas as dimensões da vida, que se desintegrariam sem ele. Para Tillich, é através deste elemento que a identidade humana se realiza, atualizando, no tempo e no espaço, aquilo que ela é em potencial. ${ }^{11}$ Nesse sentido, pode-se afirmar que esse imperativo moral é portador de uma dimensão religiosa, uma vez que responde àquilo que é incondicional ao ser humano. Nisso, é necessário um discernimento a respeito desse elemento. $\mathrm{O}$ cotidiano da vida apresenta vários imperativos e muitos deles são condicionais, apresentando opções que os substituem. Um imperativo incondicional, porém, seria aquele sem o qual o ser perde sua própria identidade. ${ }^{12}$

Qual seria, então, o imperativo moral de Gregory House? No episódio $O$ Filho do Sujeito em Coma, House está tentando obter informações de um paciente para salvar o filho deste. Este paciente despertou de um coma prolongado e, provavelmente, volte ao mesmo estado em pouco tempo. Como, ao voltar ao seu estado normal, ele começa a gozar de uma aparente boa saúde, seu interesse é o de viver seu dia desperto de maneira intensa, antes de voltar ao estado anterior. Assim, House e Wilson acompanham o homem em uma maratona de diversões on the road, na tentativa de obter informações para tratar o filho dele. O paciente, porém, faz um trato com House: para cada pergunta que o médico fizer, ele fará outra, que terá de ser respondida com sinceridade. Assim, quase no final do episódio, o homem pergunta para House por que ele se tornou médico.

Paciente: Por que você quis ser médico?

House: Esta é a grande pergunta? Eu lhe dou o aval para me humilhar e isso é o melhor que consegue fazer? Muito bem. Vamos discutir a maravilha do corpo humano...

Paciente: Não. Você é um cara curioso. Gosta de descobrir coisas. Por que não fez pesquisa? Por que trabalha com pessoas, já que as odeia tanto?

House: Complexo de Édipo. Eu buscava amor materno. Minha mãe amava o médico de um seriado...

\footnotetext{
${ }^{11}$ TILLICH, Paul. Moralidad y algo mas. Buenos Aires: America 2000, 1974. p. 9-13.

12 TILLICH, 1974, p. 13-15.
} 
Paciente: Tudo bem... Acha que não precisa de minhas respostas? Pode me perturbar.

(silêncio)

House: Quando eu tinha quatorze anos, meu pai estava servindo no Japão. Fui fazer escalada com um colega de colégio. Ele caiu, se feriu e tive que levá-lo ao hospital. Entramos pela porta errada e passamos por um cara. Ele era faxineiro. O meu amigo teve uma infecção e os médicos estavam perdidos. Então eles trouxeram o faxineiro. Ele era médico e "buraku", um dos intocáveis no Japão. Os ancestrais dele eram assassinos, criminosos. Esse cara sabia que não era aceito pela equipe. Nem tentava. Ele não se vestia bem, nem fingia ser um deles. As pessoas daquele lugar não achavam que ele tivesse algo a oferecer, exceto quando precisavam dele, porque ele estava certo. Ou seja, nada mais importava e eles tinham que acatar o que ele dizia. ${ }^{13}$

A imagem evocada por House a respeito de sua gênese vocacional se contrapõe claramente a uma filosofia de valores, que parece querer definir a moral humana em nosso contexto sociocultural. Segundo esta tendência, há uma hierarquia de valores que seriam indicativos da evolução do sujeito. O problema com esta linha de pensamento, porém, é seu vazio ontológico, pois os valores apontados como os mais elevados, geralmente, são imposições externas ao ser e não correspondem às aspirações verdadeiramente incondicionais da pessoa. $\mathrm{O}$ ser sempre precede o valor, e o valor, enraizado na realidade, realiza o ser. ${ }^{14}$ Isso encontra ecos significativos no Evangelho e parece ser um dos eixos daquilo que o texto sagrado quer firmar como verdade, a começar pelo próprio Jesus, que banqueteava com pecadores, escandalizando os fariseus, ${ }^{15}$ garantia que as prostitutas e cobradores de impostos chegariam antes deles no Reino dos Céus ${ }^{16}$ e chamava de bem-aventurados todos os excluídos de sua época ${ }^{17}$ e de sepulcros caiados aos mesmos fariseus e doutores da lei, ${ }^{18}$ condenando sua hipocrisia e dupla moral. Da mesma

\footnotetext{
${ }^{13}$ O FILHO do sujeito em coma. In: HOUSE - TERCEIRA TEMPORADA. Escrito por Doris Egan. Dirigido por Dann Attias. Produzido por Gerrit Van Der Meer e Lawrence Kaplow: Universal Studios, d2006. 1 DVD (43 min.), widescreen, color. Episódio 7.

14 TILLICH, 1974, p. 19-20.

${ }^{15}$ Lc $15,1-2$.

${ }^{16}$ Mt 21, 28-32.

${ }_{17}$ Mt 5, 1-12 e Lc 6, 20-26.

${ }^{18}$ Lc 23, 13-36.
} 
forma, Jesus é reconhecido como pedra rejeitada pelos construtores, que se tornou pedra angular, mas que continua sendo pedra de tropeço para muitos. ${ }^{19}$ Além disso, Jesus conversa com uma samaritana ${ }^{20} \mathrm{e}$ propõe um samaritano como arquétipo de misericórdia. ${ }^{21}$ Ou seja, Jesus não integra o grupo socialmente aceito como autoridade religiosa de sua época, mas é reconhecido pelos párias e intocáveis de seu contexto como salvador pelo fato de comungar com eles em seus sofrimentos e aliviá-los em suas dores. Nenhum saduceu ou fariseu fizera isso. Assim, é na tensão entre aquilo que se assume como identidade e aquilo que é exigido pelo meio, que parece se experimentar a grande crise existencial dos tempos em que vivemos.

No exemplo que House apresenta como motivação inicial para seu projeto de vida também é consonante com uma atitude existencial, na qual todas as convenções sociais são relativizadas diante das grandes emergências da vida. Tal atitude tem ecos da própria revolta existencialista, identificada de maneira especial na segunda metade do século XIX, como contraposição ao naturalismo burguês, que apregoava a adaptação da pessoa a uma suposta essência universal, alcançada por meio do conhecimento. Contra isso levantou-se a atitude de protesto contra uma cultura que, em nome do progresso e da unidade nacional, tornava o ser humano um objeto, desconsiderando todas as nuances e complexidades que cada pessoa traz em si.

O voo naturalístico do pensamento burguês fez da pessoa um campo vazio; dentro de sua sensibilidade, as impressões entram e prevalecem de acordo com o grau de sua intensidade. Em ambos os casos, o eu individual é um espaço vazio e o mensageiro de algo que não é ele próprio, algo estranho pelo qual o eu é extraviado de si próprio. Idealismo e naturalismo são iguais em sua atitude para com a pessoa existente; ambos eliminam sua significação infinita e fazem-na um espaço através do qual algo mais circula. Ambas as filosofias são expressões de uma sociedade que fora ideada para a libertação do homem, porém caiu sob a escravidão de objetos que ela própria criara. A segurança, que é garantida pelos mecanismos bem funcionantes para controle da pessoa, pelo controle organizacional da sociedade rapidamente incrementado

\footnotetext{
${ }_{19}$ At 4,11 e $1 P d 2,7-8$.

${ }^{20} \mathrm{Jo}_{\mathrm{O}} 4,1-26$.

${ }^{21}$ Lc 10, 25-37.
} 
esta segurança é comprada por um alto preço: o homem, para quem tudo isso foi inventado como meio, tornou-se um meio, ele próprio, a serviço dos meios. ${ }^{22}$

Assim como o samaritano da parábola de Lucas, o próprio House é alguém de quem não se esperaria muita coisa, segundo os padrões daquilo que se convencionou considerar como jeito de ser de um médico e até mesmo de alguém minimamente sociável. Por essa razão, a identidade de House ajuda a compreender que boa parte das atitudes e posições convencionais são mentiras existenciais às quais as pessoas se acostumaram, para melhor se adaptarem ao meio: as pessoas não são sociáveis, solidárias ou proativas por acreditarem nos valores de onde essas atitudes são oriundas. Faz-se isso por uma questão de currículo, ou seja: preciso demonstrar que falo a mesma língua do mercado, que atualmente rege as relações em nossa cultura, para não ser excluído desse meio. E o mercado não cultiva essas atitudes por acreditar nelas, mas por uma questão de oportunidade, pois essas atitudes acabam criando necessidades e, consequentemente, tornam-se novos nichos mercadológicos. Por isso, cabe-nos perguntar pelo elemento que pode desfazer estas estruturas e ajudar a revelar uma identidade mais verdadeira.

\section{Eu sou fisicamente incapaz de ser educado}

Ao lidarmos com um seriado televisivo que trabalha essencialmente com as crises humanas diante da enfermidade e das fragilidades da vida, logo poderíamos cair no paradigma do protagonista abnegado que sacrifica a si próprio para salvar aqueles que sofrem ou, ao menos, amenizar suas dores. Ou seja, como personagem principal de um seriado, House poderia, pelo senso comum, ser considerado o herói da trama, afinal, é através de seu ponto de vista que o espectador acompanha as narrativas da série. E, se assim fosse, seria sob essa perspectiva que construiríamos o ideário de identidade humana que se revela neste seriado. Sob essa perspectiva, porém, o que se obtém é uma identidade massificada: o arquétipo heroico age de acordo com aquilo que a sociedade espera dele, fazendo de todos os seus atos, exemplos a serem seguidos.

${ }_{22}$ TILLICH, Paul. A coragem de ser. 6. ed. Rio de Janeiro: Paz e Terra, 2001. p. 107-108. 
Ao observarmos o comportamento de House, as nossas intuições sobre tudo o que seria certo ou errado são frequentemente postas à prova. Em muitas circunstâncias, a conduta do personagem não apenas quebra as regras de convivência que esperamos que qualquer pessoa respeite - desde as leis aos regulamentos internos do hospital onde trabalha -, como ele também parece não responder a nenhum código deontológico que, como poderíamos imaginar, deveria ser respeitado por todos que exercem a profissão de médico. Além disso, House parece ignorar - e, muitas vezes, deliberadamente muitos dos comportamentos que costumam ser apropriados entre colegas, entre amigos ou, de uma forma mais abrangente e mais simples, entre indivíduos que se reconhecem reciprocamente como seres humanos e que, enquanto tais, se tratam com respeito..$^{23}$

Essa figura estética, por isso, ao se rebelar ou simplesmente ignorar o código de valores imposto à sua profissão e à sua própria identidade social, apresenta-se como um pária de seu contexto, o que lhe dá liberdade para não conduzir suas relações de acordo com o que se espera dele, mas a partir do que ele identifica como urgente, relevante e inadiável. House, aliás, parece encaixar-se perfeitamente na descrição feita por Moltmann a respeito do arquétipo do homem sem qualidades, elaborado por Robert Musil em seu clássico romance da década de 1930:

O homem sem qualidades luta com as possibilidades, apaixonadamente e indiferentemente ao mesmo tempo. Apaixonadamente porque esta batalha potencializa sua vitalidade; indiferentemente por saber que todas as qualidades que ele pode desenvolver nunca lhe pertencerão realmente. Ele desenvolve uma atitude experimental diante da vida, envolvendo-se como se fosse uma representação teatral, apenas na medida em que sempre consiga sair de cena. Ele é ocupado e ativo, mas não produtivo. Seu mundo desaba quando se dá conta de que, por um lado, o mundo não tem sentido e que isso, por outro lado, é algo incomunicável com toda sensibilidade de sua alma. Ele próprio vive na desilusão de que todas as possibilidades que ele já teve não passam da mesma realidade na qual ele se encontra. (Tradução nossa) ${ }^{24}$

${ }^{23}$ TESTINO, Chiara. A ética de House. In: BLITRIS. A filosofia em House. Rio de Janeiro: Best Seller, 2009. p. 46.

${ }^{24}$ MOLTMANN, Jürgen. Man - Christian Anthropology in the conflicts of the present. Philadelphia: Fortress, 1976. p. 93. 
Nesse sentido, Moltmann faz referências ao fato de que homens sem qualidades emergem de um mundo de qualidades sem homens e que tal atitude, a de renegar os valores socialmente estabelecidos, pode ser portadora de um caráter libertador e profundamente religioso. Aquele que toma a atitude de não assumir as características a ele impostas no contexto social coloca-se em relação com uma interioridade maior e mais poderosa que sua exterioridade, quase num ato de secularização do mundo - reduzindo todos os elementos da realidade à dimensão do circunstancial - e sacralização de sua interioridade - reconhecendo em sua vontade e intuição o norte que lhe aponta para um sentido incondicional de vida. Por outro lado, Moltmann alerta que esta atitude pode levar a uma alienação política, pois, se tudo no mundo é circunstancial, não vale à pena lutar por nada. ${ }^{25}$ House, porém, luta, sim, por alguma coisa, pois sua aparente indiferença, demonstrada por seu verdadeiro desprezo a regras e parâmetros preestabelecidos, é exatamente o espaço de sentido aberto para aquilo que ele considera mais importante: compreender a verdade em uma situação de sofrimento.

Assim, se House não é um herói, pois por herói, compreendese o actante sujeito dotado de valores e ideais socialmente aceitos em nome de um suposto bem-comum ${ }^{26}$ e se ele não encarna valores socialmente aceitos, mas os questiona e, na maioria das vezes, os ignora, que identidade humana pode-se compreender nele? House se revela, na verdade, um indivíduo que, solitariamente, busca sentido para seu existir ao ligar-se a alguém que é totalmente outro, ${ }^{27}$ tornando-se, nesse processo, um sujeito. Este totalmente outro, para ele, se apresenta na pessoa de cada paciente a ele encaminhado. Ali está alguém que, sendo completamente diferente dele, faz-se seu próximo e semelhante por ser portador de sofrimento. Esta questão se revela importante como chave de leitura do humano a partir de uma ideia de desencantamento, Herdeira de uma tradição cultural embasada no dever moral e de uma ética construída a partir de um idealismo elitista, parece-nos que a humanidade chega a um ponto de vazio diante dessa realidade. Desse vazio, surge a pergunta relativa ao que, afinal, nos constitui humanos e, considerando uma alteridade embasada nas dores e feridas existenciais

\footnotetext{
${ }^{25}$ MOLTMANN, 1976, p. 94-96.

${ }^{26}$ COURTÉS, Joseph; GREIMAS, Algirdas Julius. Dicionário de semiótica. São Paulo: Contexto, 2011. p. 242-243.

${ }^{27}$ REGAZZONI, Simone. A hiperética de House. In: BLITRIS. A filosofia em House. Rio de Janeiro: Best Seller, 2009. p.24-27.
} 
como possibilidade de resposta, podemos considerar que House se constitui sujeito exatamente neste tipo de alteridade, por mais egoísmo que ele aparente ter. Sem colocar-se na presença de um totalmente outro, ele se reduz às suas dores, amarguras e ao próprio fracasso que o condenou a uma enfermidade crônica. Junto a outros doentes e amargurados, porém, ele parece transformar sua miséria existencial em projeto de vida.

Um eu que se tornou matéria de cálculo e manobra deixou de ser um eu. Tornou-se uma coisa. Você deve participar de um eu a fim de conhecer o que ele é. Porém, em participando, você o transforma. Em todo o conhecimento existencial, tanto o sujeito como o objeto são transformados pelo próprio ato de conhecer. O conhecimento existencial é baseado num encontro no qual uma nova significação é criada e reconhecida. $\mathrm{O}$ conhecimento de outra pessoa, o conhecimento da história, o conhecimento da criação espiritual, o conhecimento religioso - todos tem caráter

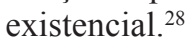

\section{Conclusão}

Assim, diante de uma pessoa enferma, House faz uma verdadeira experiência mistagógica: no limite do viver ele, busca a verdade a respeito daquele ser humano para que, vivendo ou morrendo, a vida adquira algum sentido. Encontramos nele a atitude de, sem excluir a objetividade teórica necessária para desempenhar sua função, saber mensurar esta objetividade como um elemento que não traduz o todo da pessoa em sofrimento. House sabe que só é possível tratar de uma pessoa, em termos médicos, na situação existencial desta. ${ }^{29}$ Sua obsessão por este tipo de experiência o levou a reações como a descrita no início deste artigo, ou seja, de questionamento a tudo que se encontra estabelecido como regra comportamental. House sabe que estes parâmetros morais são absolutamente superficiais e artificiais quando colocados diante do que constitui a base de construção da essência humana: a recusa em não existir, que transparece na busca por assistência diante da enfermidade.

\footnotetext{
${ }_{28}$ TILLICH, 2001, p. 98.

29 TILLICH, 2001, p. 98.
} 


\section{Referências}

BAUMAN, Zygmunt. O mal-estar da pós-modernidade. Rio de Janeiro: Jorge Zahar, 1998.

CALVANI, Carlos Eduardo. Teologia da arte. São Paulo: Paulinas. São Paulo: Fonte Editorial, 2010

COURTÉS, Joseph; GREIMAS, Algirdas Julius. Dicionário de semiótica. São Paulo: Contexto, 2011.

DE SOUZA, Vitor Chaves. "O inferno está vazio e os demônios estão aqui": uma reflexão existencialista sobre a história dos infernos em diálogo com o demoníaco em Paul Tillich. Correlatio, Brasil, 10. mar. 2012. Disponível em: <https://www. metodista.br/revistas/revistas-ims/index.php/COR/article/view/2973>. Acesso em: 22 jun. 2013. p. 63.

GOSO, Diego. Il Vangelo secondo... Dr. House. Cantulapa: Effatà, 2010.

LIPOVETSKY, Gilles. A sociedade pós-moralista. Barueri: Manole, 2005.

MOLTMANN, Jürgen. Man - Christian Anthropology in the conflicts of the present. Philadelphia: Fortress, 1976. p. 93.

MORIN, Edgar. A cabeça bem-feita: repensar a reforma. Reformar o pensamento. Rio de Janeiro: Bertrand Brasil, 2003.

O FILHO do sujeito em coma. In: HOUSE - TERCEIRA TEMPORADA. Escrito por Doris Egan. Dirigido por Dann Attias. Produzido por Gerrit Van Der Meer e Lawrence Kaplow: Universal Studios, d2006. 1 DVD (43 min.), widescreen, color. Episódio 7.

REGAZZONI, Simone. A hiperética de House. In: BLITRIS. A filosofia em House. Rio de Janeiro: Best Seller, 2009.

TESTINO, Chiara. A ética de House. In: BLITRIS. A filosofia em House. Rio de Janeiro: Best Seller, 2009. p. 46.

TILLICH, Paul. A coragem de ser. 6. ed. Rio de Janeiro: Paz e Terra, 2001. . Moralidad y algo mas. Buenos Aires: America 2000, 1974.

VINTE Vicodins. In: HOUSE - OITAVA TEMPORADA. Escrito por Peter Blake. Dirigido por Greg Yaitanes. Produzido por Marcy G. Kaplan: Universal Studios, d2011. 1 DVD (43 min.), widescreen, color. Episódio 1.

WEBER, Max. A ética protestante e o espírito do capitalismo. São Paulo: Companhia das Letras, 2012.

Recebido: 08/09/2014

Avaliado: 18/09/2014 